\title{
Management of the post-accidental situation applied to Nogent-sur-Seine nuclear power plant environment. First results of the "decontamination of soil and food chain" working group
}

\author{
J .M. Métivier ${ }^{1}$ N. Reales ${ }^{1}$, F. Gallay ${ }^{1}$, E. Allain², B. Cessac ${ }^{1}$, R. Gofette ${ }^{3}$, \\ M. Mahot ${ }^{4}$, F. Mignon ${ }^{2}$ and A. Oudiz ${ }^{1}$ \\ ${ }^{1}$ Institute for Radiological Protection and Nuclear Safety \\ ${ }^{2}$ District Agricultural and Forestry Department (Aube Administrative Area) \\ ${ }^{3}$ Veterinary division (Aube Administrative Area) \\ ${ }^{4}$ Farming Chamber (Aube Administrative Area)
}

\begin{abstract}
From the beginning of 2002, Troyes prefecture has initiated a study about the management of a nuclear crisis caused by an accident at the Nogent-sur-Seine nuclear power plant. Several working groups were created, notably the "Decontamination of soil and food chain" group.

The first results of this group, which involves the District Agricultural and Forestry Department, the Farming Chamber, the Institute for Radiological Protection and Nuclear Safety and the Veterinary Division are presented here.

The scenario that had been developed for the accident considers the release of 3 radionuclides $\left({ }^{131} \mathrm{I},{ }^{134} \mathrm{Cs}\right.$ and $\left.{ }^{137} \mathrm{Cs}\right)$ in the environment. The scale of the crisis didn't require the evacuation and the sheltering of the population during the emergency phase.

The consequences on the local agricultural products (cereal, sugar beet, vine, milk, cow meat...) have been assessed up to $50 \mathrm{~km}$ and different strategies of agricultural countermeasures have been studied regarding to the local constraints (soil types, surfaces and quantities concerned) and to the consequences of their implementation (waste types and quantities, costs). Then, decision-making diagrams summed up the technical results and allowed to deepen the global thought.
\end{abstract}

\section{INTRODUCTION}

The management of a nuclear accident begins with the emergency phase, from the facility alert notification to the end of releases in the environment. Emergency actions are then implemented to protect the health of populations but also to assess the environmental impact. As soon as releases end, the "post-accidental" phase takes over for a very variable period (ranging from a few days to several years) and on a larger land. This phase involves the implementation of strategies for the management of short and long term health, radiological, economical, etc. consequences of the environmental contamination. The implementation of such strategies, depending on the accidental situation, results from a joint thought involving the various parties concerned which must be initiated before the end of releases, or even before a possible accident in order to ensure a consistency between the actions carried out during the emergency phase and the "post-accidental" actions [1] \& [2].

In this context and on the Aube Prefect's initiative, several working groups were created in January 2002 to think about the management of a fictitious accident at the Nogent-sur-Seine NPP (France). Among them, the "Decontamination of soil and food chain" group, including local representatives from the District Agricultural and Forestry Department (DDAF), the Veterinary 
Division (DSV) and the Farming Chamber of the Aube administrative area as well as representatives from the Institute for Radiological Protection and Nuclear Safety (IRSN), were in charge of suggesting short and long term strategies to manage the agricultural, plant and animal products and the contaminated agricultural land.

This paper presents the consultation and implementation approach for the rehabilitation strategies as well as the resulted operational tools [3].

\section{ACCIDENT SCENARIO}

\subsection{Accident description}

The accident scenario adopted concerns a 900 MWe pressurized water reactor of the Nogent-sur-Seine NPP (Aube, France). It allows a fictitious shutdown of the reactor further to a complete clad failure resulting in the reactor core meltdown up to $80 \%$. Atmospheric releases are assumed to last 48 hours. Among the radionuclides released during the accident, only three main radionuclides are studied: ${ }^{131} \mathrm{I}$, ${ }^{134} \mathrm{Cs}$ and ${ }^{137} \mathrm{Cs}$. The wind direction corresponds to the prevailing winds (sector 2025) and the accident date is set to June $19^{\text {th }}$, in order to have a maximum impact on the regional agriculture (mature field crops and livestock in pasture). Figure 1 shows the distribution of ${ }^{131} \mathrm{I}$ and ${ }^{137} \mathrm{Cs}$ deposits.
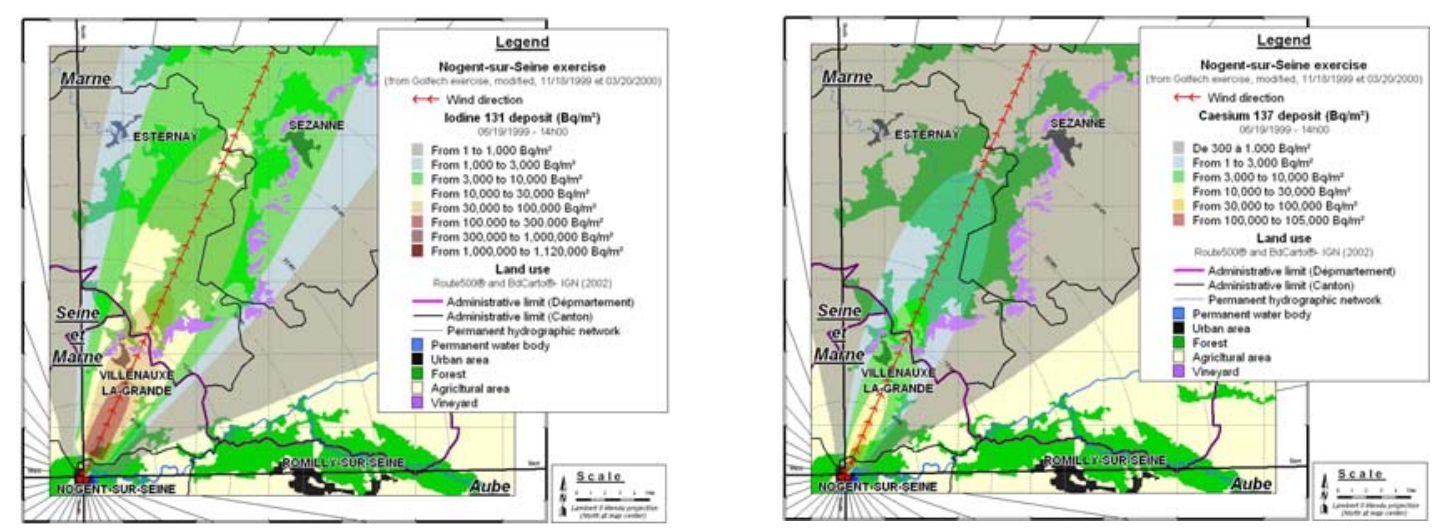

Figure 1. Deposit characteristics.

\subsection{Impact on population health}

The assessment of population exposure during the plume passage indicates a total effective dose of $10 \mathrm{mSv}$ at $1 \mathrm{~km}$ after 24 hours, requiring the sheltering of the population in a perimeter which may extend to $2 \mathrm{~km}$. As for the exposure of operators, including farmers, in charge of the rehabilitation, external dose rates due the deposits greater than $1 \mu \mathrm{Sv} / \mathrm{h}$ over the first kilometers during the first days following the accident might require the implementation of particular protections (limitation of working hours, etc.).

\subsection{Agricultural context}

Up to about fifty kilometers from the plant, the area crossed by the plume is mainly rural. The agricultural activity is mainly focused on field crops such as cereal, rape and sugar beet. There is also some viticulture (production of Champagne) from about $10 \mathrm{~km}$ from the Nogent-sur-Seine NPP. Beef cattle breeding and milk production are also practiced and represent the main agricultural and animal activities whereas breeding of sheep, goats, pigs, horses, poultry, rabbits and bees remain secondary productions and were not addressed. Lastly, forest takes up a significant surface area. 
European regulations [4] provide an indicator used to grasp the contamination level of food products depending on their nature and the type of radioelements involved: the Council Food Intervention Levels (CFILs) for the marketing of food products. For the scenario studied, the major CFIL exceedance area concerns the cow milk contamination by the ${ }^{131} \mathrm{I}$ extending to about $30 \mathrm{~km}$ from the plant, on the plume axis, during the first days following the accident. Three departments are therefore concerned, partially and unequally in terms of surface areas: the Aube, the Marne and the Seine-et-Marne departments.

\section{DEVELOPMENT OF STRATEGIES FOR THE POST-ACCIDENTAL PHASE MANAGEMENT}

\subsection{Selection of countermeasures and strategy comparison methodology}

Within the framework of the FARMING program (5 ${ }^{\text {th }}$ PCRD EURATOM) [5], a co-expertise approach was implemented between national agricultural actors and radiological protection representatives in order to assess, with regard to the French agricultural context), the technical feasibility and acceptability of a panel of agricultural countermeasures collected during the STRATEGY program (5 ${ }^{\text {th }}$ PCRD EURATOM) [6], and completed in the framework of the EURANOS program $\left(6^{\text {th }}\right.$ PCRD EURATOM) [7].

Therefore, IRSN proposed the STRATEGY countermeasures, assessed by the French actors, as the starting point for the thought of the local working group from the Aube department, as they sum up the current state of knowledge on the subject, at the European level, thus settling a basis making the implementation of strategies for the agricultural land rehabilitation easier. After a brief introduction of the major radiation protection concepts, the accident scenario as well as the STRATEGY program results were therefore submitted to the working group.

As for agricultural actors, they explicited the main issues and constraints characterizing the local agricultural networks, which allowed to assess the accident consequences on the land on the one hand, and to make a first selection among the rehabilitation actions suggested, on the other hand.

The panel of countermeasures resulting from this first selection was then reviewed, the various actions discussed, then prioritized in time and space. Once these strategies developed, and on the agricultural actors' request, IRSN assessed:

- the radiological gain, i.e. reduction of the contamination or exposure level that they involve;

- the quantity of generated waste and its contamination level;

- the exposure of operators.

Lastly, the working group globally assessed the various strategies. The results of this common thought were summed up in the form of operational diagrams, illustrating a synoptic view of the various actions and of their consequences.

\subsection{Plant agricultural productions}

\subsubsection{Field crops}

The countermeasures studied within the framework of plant productions (cereal, oilseed crops, sugar beet, potatoes and vine) are divided into three types:

- those applicable to crops present during deposition: on site littering and early removal of crops;

- those intended to modify the soil contamination: topsoil removal, deep ploughing and shallow ploughing;

- those modifying the "soil-end product" transfers: application of lime, application of potassium fertilizers and industrial transformation of the primary product. 
The agricultural and radiological context allows the elimination of some countermeasures such as:

- the topsoil removal as the soil fertility preservation appeared as a major issue for the agricultural actors. Moreover, this countermeasure has the disadvantage of producing a large quantity of waste (about 6,000,000 $\mathrm{m}^{3}$ );

- the deep ploughing which reduces the soil fertility and is not technically conceivable on local shallow soils (40 cm in average), that would induce a high decrease of fertility;

- the lime application as the soil is already sufficiently basic.

Three strategies are thus conceivable:

- On site littering of crops and subsequent burial by ploughing. This strategy offers the advantage to not generate waste, reassure consumers and not taking the risk of exposing operators to excessive external dose rates. However, it has the disadvantage to not decontaminate agriculture surfaces and bury irreversibly radionuclides in the soil. This remark may be qualified as contamination levels of the next crops are distinctly lower than CFILs owing to the contamination dilution in the soil by ploughing and root transfer;

- Early removal of crops followed by a shallow ploughing. Carried out before the first rains, this countermeasure would be used to recover the contamination intercepted by the plant aerial parts and thus limit the soil contamination. A shallow ploughing would then allow a dilution and a burial of the deposited radionuclides. However, this strategy would generate waste $(90,000$ tons of wet waste for the concerned surface area).

- Harvest in time. This countermeasure is related to the possibility of obtaining a wholesome end product like sugar. However, within the framework of this scenario, quantities concerned by this increase of value would be very limited even when this measure might have the very harmful consequences on the agricultural network image.

Figure 2 (p5) shows the efficiency of the various strategies above mentioned for cereal calculated by the ASTRAL V.2.1 software [8]. Table 1 sums up the results of the global evaluation of these strategies and Figure 3 (p5) shows the corresponding operational diagram. It should be noted that in threat phase, a protection action for silos might be envisaged as operators have time before sheltering.

Table 1. Evaluation of advantages and drawbacks resulting from the application of the various strategies.

\begin{tabular}{|c|c|c|c|}
\hline Strategy & $\begin{array}{l}\text { On site burial of crops for } \\
\text { which harvest is not } \\
\text { recoverable } \\
\text { End product > CFILs }\end{array}$ & $\begin{array}{l}\text { Early removal of crops } \\
\text { (1 to } 3 \text { months before "normal" date) }\end{array}$ & $\begin{array}{l}\text { Harvest in time } \\
\text { End product }<\text { CFILs }\end{array}$ \\
\hline $\begin{array}{l}\text { Crop and } \\
\text { surface } \\
\text { area }\end{array}$ & $\begin{array}{l}\text { Cereal, potatoes and other crops } \\
\text { in open field: } 15,000 \text { acres }\end{array}$ & Developed aerial parts: 15,000 acres & $\begin{array}{l}\text { Sugar beet: } 75 \text { acres, } 1,800 \text { tons } \\
\text { of FM - } 360 \text { tons of sugar }\end{array}$ \\
\hline $\begin{array}{l}\text { Effect on } \\
\text { soil }\end{array}$ & No soil decontamination & $\begin{array}{l}\text { Soil decontamination varying depending on: } \\
\text { - the vegetative state of crops during the } \\
\text { deposition } \\
\text { - the climatic conditions before } \\
\text { implementing the countermeasure } \\
\text { (interception from } 25 \text { to } 50 \% \text { of the deposit by the tree cover) }\end{array}$ & $\begin{array}{l}\text { Low soil decontamination } \\
\text { (Leaching of the intercepted deposit) }\end{array}$ \\
\hline Waste & No waste & $\begin{array}{l}\text { Large quantity of wet organic waste: } \\
90,000 \text { tons }\end{array}$ & $\begin{array}{l}\text { Large quantity of waste: } 2,000 \\
\text { tons of Fresh Organic Material }\end{array}$ \\
\hline
\end{tabular}

\subsubsection{The particular case of vineyard}

Although no vineyard appears in the CFIL exceedance area, and that wine harvest will be carried out only 3 months later and that vinification reduces the transfer of radionuclides (Caesium) from grapes to wine, the main problem of the "Champagne" (very high added value product and mainly intended for export) production network is to manage its image. 


\subsection{Animal agricultural productions}

The two major animal productions present in the area are the cow milk production and the beef cattle breeding.

\subsubsection{Milk network}

Considering that no countermeasure is implemented, i.e. animals (livestock comprising about 1,500 heads) are left in pastures during and after the releases, the CFIL exceedance area for ${ }^{131} \mathrm{I}$ extends beyond about $30 \mathrm{~km}$ (Figure 4), 2 days after the accident, but then rapidly reduces (17 km, 15 days later and $5,5 \mathrm{~km}$, one month later).

For cesiums, CFILs are exceeded at about $10 \mathrm{~km}$ and maintain during several months over a few kilometers.

During the first two weeks, about 550,000 liters of milk would be produced, 95\% of which would be contaminated by ${ }^{131}$ I only.

During the next 3 months, about 70,000 liters of contaminated milk would be produced, exceeding the CFILs both for ${ }^{131} \mathrm{I}$ and especially for cesiums.

The management strategies for these two types waste would be different. In the first case, a strategy based on the natural decay of iodine 131 would be conceivable (stabilization and storage of milk) and in the other case, it should be adapted to long-lived radioelements.

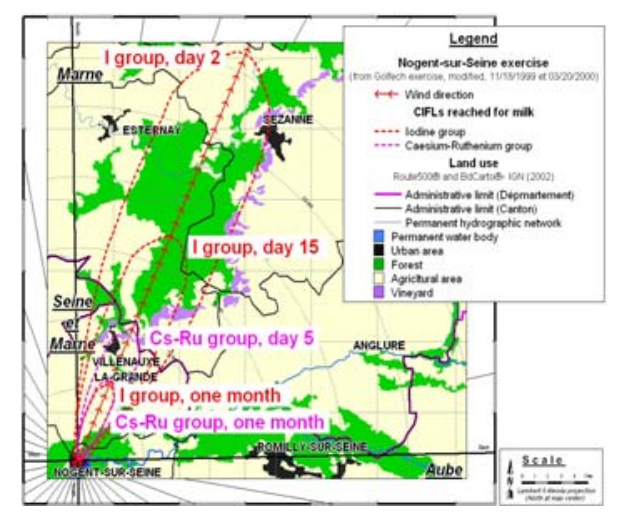

Figure 4. Time extensions of the milk marketing limits for iodine and cesiums.

\subsubsection{Meat network}

The beef breed livestock contamination is mainly due to caesiums. Extended to the maximum, the CFIL exceedance reaches about $15 \mathrm{~km}$, one month after the accident. The concerned livestock comprises a hundred of heads approximately.

\subsubsection{Selection of countermeasures conceivable for milk and meat networks}

Whether it is dairy cows or beef breeds, there are two type of conceivable countermeasures: those intended to improve pastures (pasture ploughing with application of fertilizers, etc.) and those directly applicable to animals (shrinkage from pasture, wholesome food distribution, Prussian blue distribution, clay distribution, etc.).

The conceivable strategies combine, for example, the "Stop grazing”, “clean feeding” and "Improvement of pasture areas" countermeasures. However, their efficiencies may vary: for example, in the vicinity of the plant, the CFIL exceedance durations in milk vary from 80 to about 10 days for Cs (see Figure 5) and from 40 days to one week for iodine. In meat, they vary from 10 to 4 months for Cs. However, given the small size of livestock (1,500 dairy cows and 100 beef cattle) and the minor agricultural issue associated with this network in the concerned sector. For the working group, the cattle slaughter is judged the most conceivable solution. In fact, this countermeasure offers the advantage to solve the problem related to the contaminated milk management and reassure the population about the intentions of authorities and networks (milk and meat). This solution is also advantageous concerning the waste management (900 tons of carcasses or $500 \mathrm{~m}^{3}$ of ashes in case of incineration instead of 600,000 liters of contaminated milk), it however emphasizes the social and economic impact on the affected farms and also may require the construction on the contaminated area of specific facilities. Figure 6 shows the decision diagram related to the milk and cattle inventory management. 


\subsection{Management strategies for related products}

Large forest areas are crossed by the plume and the contamination levels of the hunting (boars, rabbits, etc.) and picking (mushrooms, berries, etc.) products are likely to exceed the CFILs, in particular for cesium. Cultivated vegetables (salads, etc.) in gardens may have high contamination levels and represent an uncontrolled source of exposure by ingestion. Measures like the forest closure (with beats to regulate the population of animals, possible vectors of contamination) and the prohibition to consume products from private gardens would be ordered.
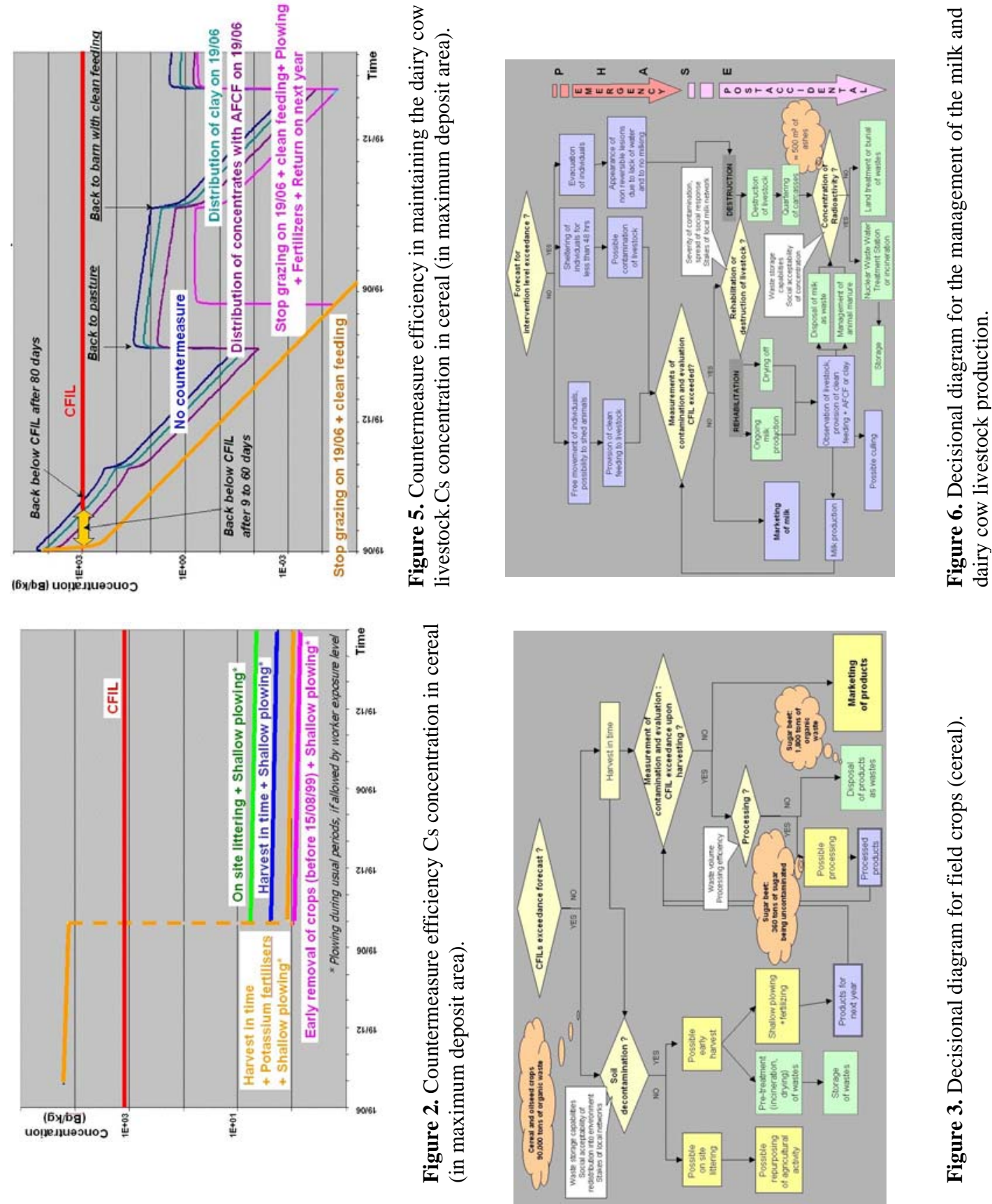

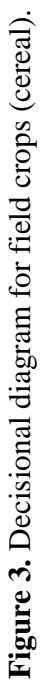




\section{CONCLUSION}

The thought conducted on the management of the post-accidental phase following a nuclear accident occurred at the Nogent-sur-Seine NPP grouped together various local, regional and national actors from the agricultural and radiological protection community. Various strategies were studied. Those, which were adopted are used as solutions submitted to the department Prefect who is the final decision maker.

It is important to note that the strategies envisaged throughout this work remain highly related to the accident characteristics (extent, radionuclides, accident date) and to the local agricultural characteristics (economical, strategies, pedological, agronomical). Consequently, it appears no countermeasure or strategic decision can be considered totally not applied, or on the opposite have a universal value, within the framework of a more global thought (national, international).

The work carried out confirms the need for preparing, in "peace time" the various actors who might be concerned, for a more efficient and relevant action. These actors would be responsible, in crisis situation, for taking rapidly decisions implying the safety of populations (implementation of actions intended to protect the population, monitor food products, etc.). But many of them have often only a few radiological protection elements at their disposal, which would not enable them to grasp globally the situation and its evolution, prerequisite necessary for implementing protection or rehabilitation actions. This local working group therefore allowed to better identify the information needs of actors external to radiological protection, who might need to intervene in post-accidental situation.

The working group also highlighted the importance of an analysis in time and a consistency between the short, medium and long term management, as the application of some countermeasures may, at first, limit the long-term rehabilitation capacity or generate further harmful consequences (radioelements migrating to water tables). The decisional diagrams illustrate tools used to direct, since the emergency phase, the short term strategies depending on the long term strategies envisaged by the concerned actors.

The results of this case study were then presented to the members of the FARMING network, whose results had initially provided the local thought basis, during its closure seminary. Local operators used this presentation, and the discussion resulting from it, to demonstrate to national operators, from an actual case, the difficulties encountered in the field to implement the national requests. This exchange between local and national actors must therefore continue in order to develop post-accidental rehabilitation strategies adapted to the public opinion request but also to the reality of local actors.

This work also emphasized:

- the need to develop knowledge in certain fields or on others conceivable countermeasures, such as the agricultural activity reorientation towards non-food productions (biofuel for example),

- the interest to appreciate the close relationship between the various environmental contexts (water, forest, soils, etc.),

- the necessity to carry on works on other less known themes (including quality and potability of surface and ground water).

This study confirms the interest of this type of work and the need to pursue them within an interdisciplinary framework allowing to grasp all field realities, related to all concerned actors and to develop the tools and conditions making the communication between these actors easier. For instance, this study was also presented to the French FARMING network members in order to compare the national and local viewpoints on this particular case., allowing interesting views for a more global study to others national nuclear sites. 


\section{References}

[1] J.M. Métivier, Documents for decision making during intermediate and late phases after a major nuclear accident - Radioprotection - Colloques, volume 37, C1-1049, February 2002.

[2] O.M.M.BADIE Methodology for evaluation of post-accidental rehabilitation strategies Radioprotection - Colloques, volume 37, C1-1073, February 2002.

[3] N.REALES, Méthodologie de construction de stratégies de gestion d'un territoire agricole contaminé en phase post-accidentelle - Résultats du groupe de travail « Décontamination des sols et chaîne alimentaire », rapport IRSN/DEI/SARG (under rewiewing).

[4] Regulation (EC) N $178 / 2002$ of the European Parliament and of the council of 28 January 2002.

[5] http://www.ec-farming.net

[6] http://www.strategy-ec.org.uk/

[7] http://www.euranos.fzk.de/

[8] P. Calmon \& C. Mourlon, ASTRAL V2.1 code - Equations and Parameters, (2003), report IRSN/DPRE/SERLAB n $03-16$. 